\title{
BOILER DRUM-LEVEL MODELING
}

\author{
S. R. Tawfeic \\ Department of mechanical power \& energy, Minia University, Minia, Egypt \\ Received 1 April 2013; accepted 5 May 2013
}

\begin{abstract}
In this paper, a mathematical model is developed to describe the dynamics of the drum-level of a natural circulation boiler. A boiler-drum is divided into two parts; the upper part contains saturated steam while the lower part contains a steam/water mixture. The ratio of the steam in that mixture is defined in this work as the steam volumetric ratio. On the other hand, balance equations are applied to the drum. The resulting equations are used to model the drum-level. The importance of the resulting model comes from the direct modeling of drum level which is usually computed off-line with the aid of empirical formulas and assumptions. Safe operation of boilers requires perfect level controller which cannot be designed without proper modeling. Simulation of the water level dynamics for step changes in heat rate and steam demand are compared with those in the literature. The results show that the drum level can be obtained from the basic balance equations.
\end{abstract}

Keywords: water level dynamics, Drum-type Boilers, Natural circulation, and boiler modeling, Simulation.

\section{Introduction}

A dramatic shift from the use of nuclear power generation plants is expected very soon, due to the upset of repeated nuclear accidents caused by these plants. Strong tendency for this shift is led by industrial countries, especially after the recent Fukushima nuclear crisis. Fossil-fuel power plants with large boilers are expected to replace such huge capacity units. Drum-type boilers use the principle of natural water circulation, where the density differences causes circulation of water in the down comer riser loop. Addition of heat causes the creation of steam bubbles in the riser tubes which are naturally separated from the saturated water in the drum. The primary function of boiler system is to balance load demand with generator output energy While, maintaining the internal variables of the system at designated values.

It is important to realize that drum-type boiler is a highly nonlinear complex system and it is difficult to design an effective controller for such system with Shrink/Swell phenomena. Therefore, thorough understanding of the process is essential for the design of the boiler control system. Modeling of drum boiler dynamics was considered by many researchers over the years. A lot of research has been devoted to model-based control, Wen Tan et al. [1] and [2] designed a linear controller to work in a carefully selected operating range of a highly non-linear model. Analysis of the response of a thermal power plant using optimal control of drum level is given by Eun. Gee. Kim [3]. Caifen Fu et al. [4] designed a robust PI controller to study the performance of a benchmark boiler system. Tuning rules for a structured PID controller of a boiler-turbine unit are introduced by Wen Tan et al. [5]. Hamdi A. Awad \& Saad M. Hewaidy [6], Addel Ben-Abdennour, \& Kwang Y. Lee [7], \& Ali Ghaffari et al. [8] used fuzzy logic control strategies. Hèctor, G.C. et al. [9] used sliding-mode control to achieve robust tracking of drum-type steam generating units. Yu Nanhua et al. [10] Introduced an adaptive derivative action to monitor steam

Corresponding author.

E-mail address: shehabrt@link.net 
flow, and weaken the effect of "false water level". The development of a dynamic simulation model and its application in the study and design of a new control philosophy and turbine bypass system to meet the operational requirements is presented by W. J. Peet, \& T. K. P. Leung [11]. Pang-Chia Chen \& Jeff S. Shamma [12] introduced a gainscheduled approach for boiler-turbine controller design. Simulation of the startup behavior of controlled circulation and natural circulation boilers is given by Bin Li, Tingkuan Chen et al. [13]. A furnace model describing the combustion in a model of an air-flue gas which includes a bubbling fluidized bed and a model for a water-steam circuit describing heat transfer from hot flue gases to water and steam is presented by Tuomas Kataja \& Yrjö Majanne [14]. The results of a comparison of four finite-volume-algorithms for the dynamic simulation of natural circulation steam generators are reported by Heimo Walter [15]. K.L. Lo \& Y. Rathamarit [16] examined state estimation using an unscented Kalman filter.

The development of a mathematical model for drum type boilers requires a combination of non-linear equations, to describe the evaporation in the vertical tubes and the phase separation in the steam drum as shown by Adam, E.J, Marchetti, and J.L [17]. L. C. Gómez, F. E. Milioli [18], \& M.H. Zhang et al. [19] studied two phase flow inside the risers, while H.E. Emara-Shabaik et al. [20] introduce a model to predict riser's temperature.

Modeling water level is a quite complicated task because of the complex flow patterns inside the drum. Although the drum level is very important parameter to control for safe operation of boilers, none of the available literature presents a complete model for the system including the drum level. H. Kim, \& S. Choi, [21] and Åström, K.J., \& Bell, R.D. [22] present models to describe the volume of steam under the water level which can be used indirectly to evaluate the level. An Important problem with steam volume evaluation given in thesis papers is the use of empirical models to simulate the steam flow rate out of the surface. On the other hand, direct evaluation of drum level is given by F. M. Mansour et al. [23], yet the model does not account for the volume of steam in the mixture which is responsible for swell and shrink phenomena and is essential for accurate evaluation of the drum level.

In this work, a complete dynamic model including the level inside the drum is presented. Evaluation of the level is based on the elementary equations. The simulator is based on three models; one uses global mass and energy balance to capture the behavior of the system, the second one to describe the operation in the riser downcomer loop and the third for the level inside the drum. The behavior of drum level is directly obtained using a combination of the energy equation applied to the drum, and the fact that, the rate of change of volume of the system is zero. The mixture of water and steam below the level is given by another equation describing the volumetric ratio of steam in the mixture. The results from the presented model are compared with those of Åström, K.J., \& Bell, R.D. [22] to examine the accuracy of the model.

Journal of Engineering Sciences, Assiut University, Faculty of Engineering, Vol. 41, No. 5, September, 2013, E-mail address: jes@aun.edu.eg 


\section{Mathematical modeling}

\section{1. Model formulation}

Fig. 1 shows a schematic diagram of natural circulation drum type boiler. The heat released from the combustion of fuel is used to evaporate water in the riser tubes. The resulting difference in water densities causes the circulating flow of water. Accordingly, the water-steam mixture enters the lower part of the drum. Steam flows out at the top of the drum as demanded. Feed-water makeup is supplied to the lower part of the drum. Modeling of the boiler includes the essential inputs and outputs needed for the overall plant operation and control. Linearization about normal operating conditions is given and the shrink/swell phenomenon is incorporated in the model.

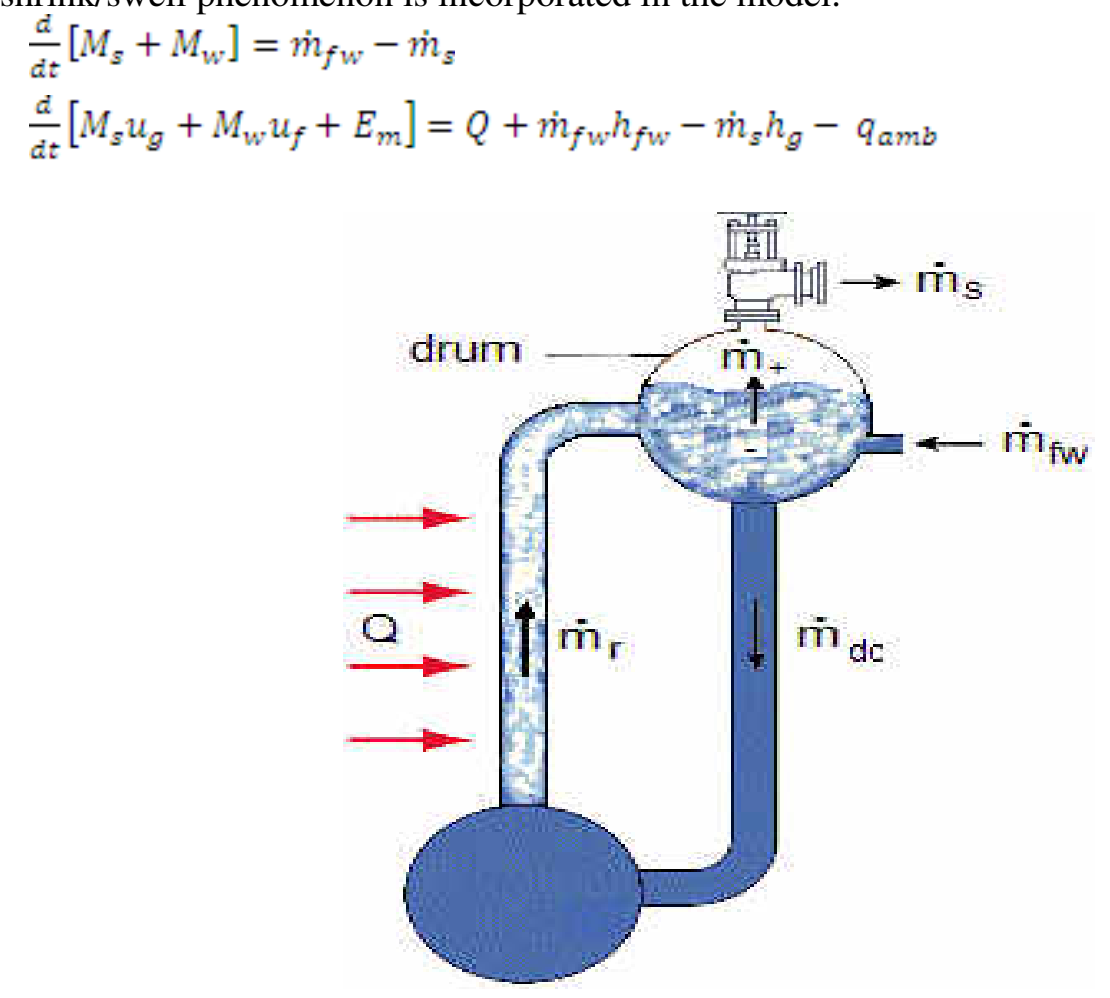

Fig. 1. Schematic diagram of the boiler natural circulation loop

$E_{m}=m_{t} C_{p} t_{\text {sat }}$, is the total energy stored in the metal of the steel drum and tubes, where the wall temperature of the metal is assumed to be strongly correlated to the saturation temperature at the operating condition ${ }^{t_{\text {sat }}}$. The heat loss to the ambient $q_{\text {amb }}$ is neglected.

Assuming uniform saturation pressure in the drum and tubes

$\mathrm{M}_{\mathrm{g}}=\rho_{\mathrm{g}} \mathrm{V}_{\mathrm{g}}$, and $\mathrm{M}_{\mathrm{w}}=\rho_{\mathrm{f}} \mathrm{V}_{\mathrm{w}}$

Journal of Engineering Sciences, Assiut University, Faculty of Engineering, Vol. 41, No. 5, September, 2013,E-mail address: jes@aun.edu.eg 


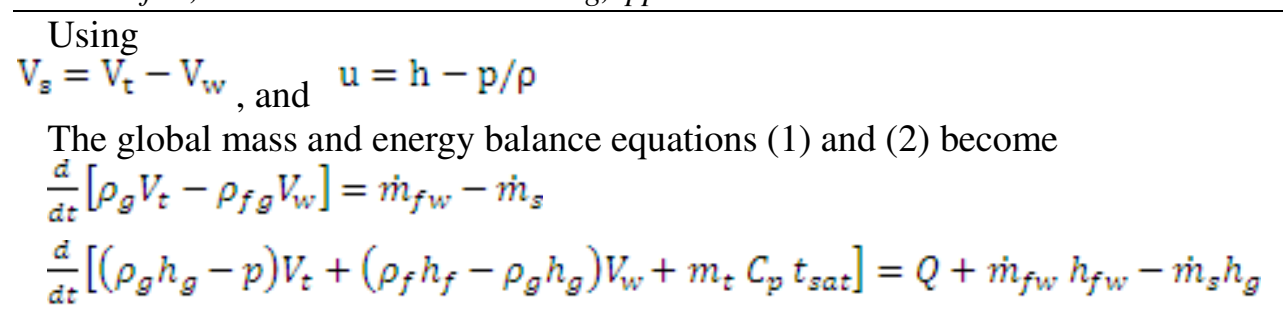

Since the saturated properties of water and steam are functions of the pressure only, the differentiation of equations (5) and (6) include partial differential of these terms with respect to pressure at the equilibrium condition giving rise to the following equations

$$
\begin{aligned}
& -\rho_{f g} \frac{d W_{t}}{d t}+\left\{\frac{\partial \rho_{g}}{\partial p} V_{t}-\frac{\partial \rho_{f g}}{\partial p} V_{w}\right\} \frac{d p}{d t}=m_{f w}-m_{g} \\
& \left(\rho_{f} h_{f}-\rho_{g} h_{g}\right) \frac{d W_{w}}{d t}+\left\{\left(\frac{\partial\left(\rho_{g} h_{g}\right)}{\partial p}-1\right) V_{t}+\frac{\partial\left(\rho_{f} h_{f}-\rho_{g} h_{g}\right)}{\partial p} V_{w}+m_{t} C_{p} \frac{\partial t_{g a t}}{\partial p}\right\} \frac{d p}{d t}=Q+ \\
& \dot{m}_{f w} h_{f w}-\dot{m}_{g} h_{g}
\end{aligned}
$$

They can be written in the following forms

$$
-\rho_{\mathrm{fg}} \frac{\mathrm{d} w_{\mathrm{W}}}{\mathrm{dt}}+\left\{C \mathrm{p}_{1} \mathrm{~V}_{\mathrm{sw}}+C \mathrm{p}_{2}\right\} \frac{\mathrm{dp}}{\mathrm{dt}}=\mathrm{m}_{\mathrm{ftw}}-\mathrm{m}_{\mathrm{s}}
$$

And

$$
\left(\rho_{\mathrm{f}} \mathrm{h}_{\mathrm{f}}-\rho_{\mathrm{g}} \mathrm{h}_{\mathrm{g}}\right) \frac{\mathrm{d} w_{\mathrm{W}}}{\mathrm{dt}}+\left\{\mathrm{Cp}_{3} \mathrm{~V}_{\mathrm{w}}+\mathrm{C} \mathrm{p}_{4}\right\} \frac{\mathrm{dp}}{\mathrm{dt}}=\mathrm{Q}+\mathrm{m}_{\mathrm{fw}} \mathrm{h}_{\mathrm{fw}}-\mathrm{m}_{\mathrm{g}} h_{g}
$$

Where ${ }^{C p_{1}}, C p_{2}, C p_{3}$, and $C p_{4}$ are constants given by

$$
\left\{\begin{array}{l}
C p_{1}=-\frac{\partial \rho_{f g}}{\partial p}, \\
C_{p 2}=\frac{\partial \rho_{g}}{\partial p} V_{t}, \\
C p_{3}=\frac{\partial\left(\rho_{f} h_{f}-\rho_{g} h_{g}\right)}{\partial p}, \text { and } \\
C p_{4}=\left(\frac{\partial\left(\rho_{g} h_{g}\right)}{\partial p}-1\right) V_{t}+m_{t} C_{p} \frac{\partial t_{g a t}}{\partial p}
\end{array}\right.
$$

Due to the complexity of the resulting highly non-linear system equations, the constant coefficients in the equations will be collected and initiated by a capital ${ }^{C}$ to reduce the size of the equations and make the linearization process less prone to errors.

\section{2. The downcomer-riser flow loop}

The balance equations applied to the riser tubes are

$$
\begin{aligned}
& \frac{d}{d t}\left(M_{a r}+M_{w r}\right)=\dot{m}_{d e}-\dot{m}_{r} \\
& \frac{d}{d t}\left(M_{s r} h_{g}+M_{w r} h_{f}-p V_{r}+m_{r} C_{p} t_{s a t}\right)=Q+m_{d e} h_{f}-m_{r} h_{r}
\end{aligned}
$$

Where ${ }^{M_{s r}}$, and ${ }^{M_{W r}}$ are the masses of steam and water inside the risers.

Journal of Engineering Sciences, Assiut University, Faculty of Engineering, Vol. 41, No. 5, September, 2013, E-mail address: jes@aun.edu.eg 
Assuming linear distribution of steam-mass fraction, Aström \& Bell [22] show that the average volumetric ratio of the steam inside the risers is given by:

$$
\alpha_{w}=\frac{-\rho_{f}}{\rho_{f g}}\left(1+\frac{\rho_{g}}{\rho_{f g} x_{Y}} \ln \left(1-\frac{\rho_{f g}}{\rho_{g}} x_{r}\right)\right)
$$

Using the above equation, total steam and water volumes inside the risers can be evaluated as

$$
V_{s r}=\alpha_{v} V_{r} \text { and } V_{w r}=\left(1-\alpha_{v}\right) V_{r}
$$

With the aid of (15), equations (12), and (13) become

$$
\begin{aligned}
& \frac{d}{d t}\left(\rho_{f}+\alpha_{v} \rho_{f g}\right) V_{r}=\dot{m}_{d e}-m_{r} \\
& \frac{d}{d t}\left\{\left[\rho_{f} h_{f}+\alpha_{v}\left(\rho_{g} h_{g}-\rho_{f} h_{f}\right)-p\right] V_{r}+m_{r} C_{p} t_{g a t}\right\}=Q+\dot{m}_{d c} h_{w}-\dot{m}_{r} h_{r}
\end{aligned}
$$

Canceling out ${ }^{m_{r}}$ from equations (16), and (17) results the following

$$
\begin{aligned}
& \frac{d}{d t}\left\{\left[\rho_{f} h_{f}+\alpha_{v}\left(\rho_{g} h_{g}-\rho_{f} h_{f}\right)-p\right] V_{r}+m_{r} C_{p} t_{s a t}\right\}-h_{r} V_{r} \frac{d}{d t}\left(\rho_{f g} \alpha_{v}+\rho_{f}\right)= \\
& Q-m_{d e} x_{r} h_{f g}
\end{aligned}
$$

This can be reduced to the form

$$
\left(C p_{5}-h_{r} C p_{6}\right) \frac{d p}{d t}+\left(C x r_{1}-h r C x r_{2}\right) \frac{d x_{Y}}{d t}=Q-m_{d v} x_{r} h_{f g}
$$

Where

$$
\begin{aligned}
& C p_{5}=\left[\frac{\partial \rho_{f} h_{f}}{\partial p}+\alpha_{v} \frac{\partial\left[\rho_{g} h_{g}-\rho_{f} h_{f}\right)}{\partial p}-1\right] V_{r}+m_{r} C_{p} \frac{\partial t_{g a t}}{\partial p}, \\
& C p_{6}=\left[\frac{\partial \rho f}{\partial p}+\alpha_{v} \frac{\partial \rho_{f g}}{\partial p}+\rho_{f g} \frac{\partial \alpha_{v}}{\partial p}\right] V_{r}, \\
& C x r_{1}=\left(\rho_{g} h_{g}-\rho_{f} h_{f}\right) V_{r} \frac{\partial \alpha_{V}}{\partial x_{x}}, \text { and } \\
& C x_{2}=\rho_{f g} V_{r} \frac{\partial{x_{v}}_{v}}{\partial x_{x}}
\end{aligned}
$$

Also from eq. (16) we have

$$
\begin{aligned}
\dot{m}_{r} & =m_{d e}-\frac{d}{d t}\left(\rho_{f}+\alpha_{w} \rho_{f g}\right) V_{r} \\
& =m_{d e}-\frac{\partial}{\partial p}\left(\rho_{f}+\alpha_{v} \rho_{f g}\right) V_{r} \frac{d p}{d t}-V_{r} \rho_{f g} \frac{\partial \alpha_{V}}{\partial x_{Y}} \frac{d x_{Y}}{d t} \\
& =m_{d e}+C p_{r} \frac{d p}{d t}+C x_{r} \frac{d x_{r}}{d t}
\end{aligned}
$$

Where: ${ }^{C p_{r}}$, and $C x_{r}$ are constants evaluated at the equilibrium operating condition and are given by

$$
\begin{aligned}
& C p_{r}=-\frac{\partial}{\partial p}\left(\rho_{f}+\alpha_{w} \rho_{f g}\right) V_{r}, \text { And } \\
& C x_{r}=-\rho_{f g} V_{r} \frac{\partial \alpha_{V}}{\partial x_{Y}}
\end{aligned}
$$

Journal of Engineering Sciences, Assiut University, Faculty of Engineering, Vol. 41, No. 5, September, 2013,E-mail address: jes@aun.edu.eg 
S. R. Tawfeic, Boiler Drum-Level Modeling, pp. 1812 - 1829

Asström \& Bell [22] described the natural circulation inside the riser-downcomer loop as follows

$$
\left(L_{r}+L_{d e}\right) \frac{d m_{d e}^{d e}}{d t}=-\rho_{f g} \alpha_{v} V_{r} \mathrm{~g}-\frac{k}{2} \frac{m_{d e}^{n}}{\rho_{f} A_{d l e}}
$$

\subsection{Drum}

Modeling water the drum water level is a very complicated task. Poor control of the drum level is expected due to the non-minimum phase behavior caused by the complicated swell and shrink phenomena.

There are many efforts to model the drum-water level. Kim \& Choi [21] use drift velocity of steam bubbles to evaluate the flow rate of steam crossing the water surface taking into account constitutional equations for the condensation rate to compute the volume of steam contributing to the drum water level. Aström \& Bell [22] use mass balance equations to evaluate the volume of steam under water level with the aid of an empirical model describing the steam flow rate out of the surface. Bin Li et al. [13] \& Adam, E.J. \& Marchetti, J.L. [17] divide the drum into two phases above and below water level and apply the basic conservation equations together with some empirical formulas on each phase to evaluate the volume of steam under water level.

All of the above researchers indirectly evaluate the level inside the drum using volumes of steam and water below drum level. Direct modeling of drum water level is carried out by F. M. Mansour et al. [23] but their work doesn't account for the contribution of the volume of steam under water level to the level of the drum.

Fig. 2 shows a schematic representation of a boiler drum. The drum is divided into two zones. The first zone below water level is filled with steam water mixture while the upper zone is filled with steam.

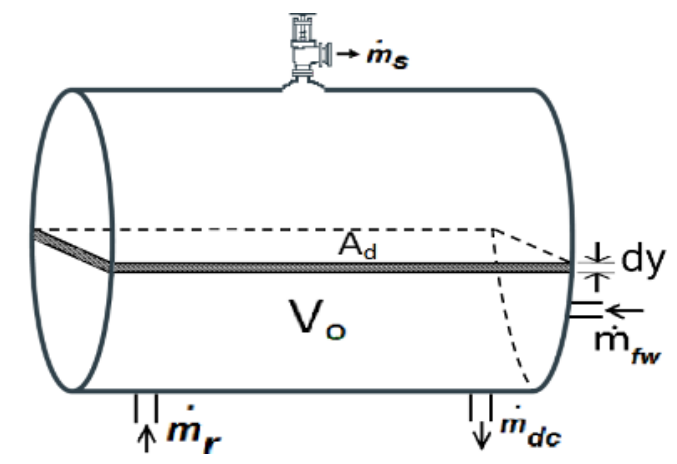

Fig. 2. Schematic representation of the drum

\section{3. 1. Volumetric ratio of the mixture}

Denoting the initial volume of the mixture by ${ }^{V_{\odot}}$, the volume of mixture under water surface can be given by

Journal of Engineering Sciences, Assiut University, Faculty of Engineering, Vol. 41, No. 5, September, 2013,E-mail address: jes@aun.edu.eg 
$V_{m}=\left(V_{0}+A_{d} y\right)$

Where ${ }^{A_{d}}$ is the water surface at the operating level as shown in Fig. 2.

It is easy to show that the volumetric ratio of the steam in the mixture ${ }^{V_{m}}$ is given by

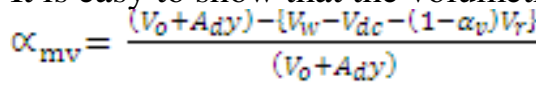

With the aid of eq. (25), the total volume of the boiler system can be given as

$V_{t}=V_{w}+\left(V_{d}-V_{m}\right)+\propto_{m v} V_{m}+a_{v} V_{r}$

Differentiating eq. (26) using the fact that ${ }^{V_{t}}$ is constant yields

$\frac{d V_{W}}{d t}+\frac{\partial a_{V}}{\partial p} V_{r} \frac{d p}{d t}+\frac{\partial{a_{V}}_{V}}{\partial x_{Y}} V_{r} \frac{d x_{r}}{d t}-\left(1-\propto_{m W}\right) A_{d} \frac{d y}{d t}+V_{m} \frac{d \varsigma_{m v}}{d t}=0$

This can be written in the form

$\frac{d V_{W}}{d t}+C p_{7} \frac{d p}{d t}+C x r_{3} \frac{d x_{T}}{d t}-\left(1-\propto_{m W}\right) A_{d} \frac{d y}{d t}+V_{m} \frac{d \infty_{m V}}{d x}=0$

Where

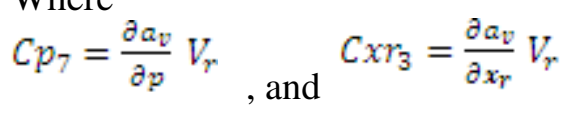

\section{3. 2. Mass balance}

Applying the mass balance equation to the drum gives

$\frac{d}{d t}\left\{\rho_{f}\left(1-\propto_{m w}\right) V_{m}+\rho_{g} \propto_{m w} V_{m}+\rho_{g}\left(V_{d}-V_{m}\right)\right\}=\left(m_{r}-m_{d v}\right)+\left(\dot{m}_{f w}-\dot{m}_{s}\right)$

Or

$$
\begin{aligned}
& \left(1-\propto_{m w}\right) \rho_{f} A_{d} \frac{d y}{d t}+\left(1-\propto_{m w}\right) V_{m} \frac{\partial \rho_{f}}{\partial p} \frac{d p}{d t}-\rho_{f} V_{m} \frac{d \propto_{m v}}{d t}+\propto_{m w} \rho_{g} A_{d} \frac{d y}{d t}+ \\
& \propto_{m w} V_{m} \frac{\partial \rho_{g}}{\partial p} \frac{d y}{d t}+\rho_{g} V_{m} \frac{d \propto_{m w}}{d t}+V_{d} \frac{\partial \rho_{g}}{\partial p} \frac{d p}{d t}-\rho_{g} A_{d} \frac{d y}{d t}-V_{m} \frac{\partial \rho_{g}}{\partial p} \frac{d p}{d t}=\left(m_{r}-\dot{m}_{d d}\right)+ \\
& \left(\dot{m}_{f w}-\dot{m}_{s}\right)
\end{aligned}
$$

It can easily be shown that

$$
V_{w m}=\left(V_{w}-V_{d e}-\left(1-a_{w}\right) V_{r}\right)
$$

Replacing the term $\left(1-\propto_{m v}\right) V_{m}$ from eq. (31), using its equivalent term $\left(V_{w}-V_{d e}-\left(1-a_{v}\right) V_{r}\right)$ as given by eq. (32) gives

$$
\begin{aligned}
& {\left[\left(\frac{\partial \rho_{f}}{\partial p}-\frac{\partial \rho_{g}}{\partial p}\right)\left(V_{w}-V_{d e}-\left(1-a_{v}\right) V_{r}\right)+\frac{\partial \rho_{g}}{\partial p} V_{d d}\right] \frac{d y}{d t}+\left(1-\propto_{m w}\right)\left(\rho_{f}-\rho_{g}\right) A_{d} \frac{d y}{d t}-} \\
& \left(\rho_{f}-\rho_{g}\right) V_{m} \frac{d \alpha_{m v}}{d t}=\left(\dot{m}_{r}-\hat{m}_{d d}\right)+\left(\hat{m}_{f w}-\hat{m}_{s}\right)
\end{aligned}
$$

Substituting from eq. (21) into eq. (33) gives

$$
\begin{aligned}
& {\left[\left(\frac{\partial \rho_{f}}{\partial p}-\frac{\partial \rho_{g}}{\partial p}\right)\left(V_{w}-V_{d g}-\left(1-a_{v}\right) V_{r}\right)+\frac{\partial \rho_{g}}{\partial p} V_{d}-C_{p r}\right] \frac{d y}{d t}-C_{x r} \rho_{f g} \frac{d x_{Y}}{d x}-(1-} \\
& \left.\alpha_{m v}\right) \rho_{f g} A_{d} \frac{d y}{d t}+\rho_{f g} V_{m} \frac{d x_{m v}}{d t}=\left(\dot{m}_{f w}-\dot{m}_{g}\right)
\end{aligned}
$$

Journal of Engineering Sciences, Assiut University, Faculty of Engineering, Vol. 41, No. 5, September, 2013,E-mail address: jes@aun.edu.eg 


\section{3. 3. Energy balance}

The energy equation applied to the drum is

$$
\begin{array}{r}
\frac{d}{d t}\left\{\rho_{v} V_{w m} u_{f}+\rho_{s} V_{s m} u_{g}+\rho_{g}\left(V_{d}-V_{m}\right) u_{g}+m_{d} C_{p} t_{g a t}\right\} \\
=\left(m_{r} h_{r}-\dot{m}_{d c} h_{f}\right)+\left(\dot{m}_{f w} h_{f w}-\dot{m}_{g} h_{g}\right)
\end{array}
$$

This can be reduced to

$$
\begin{aligned}
& \frac{d}{d t}\left\{\left(1-\alpha_{m w}\right)\left(\rho_{f} h_{f-} \rho_{g} h_{g}\right) V_{m}+\left(\rho_{g} h_{g}-p\right) V_{d}+m_{d} C_{p} t_{\text {gat }}\right\}=\left(m_{r} h_{r}-\right. \\
& \left.m_{d v} h_{f}\right)+\left(\dot{m}_{f w} h_{f w}-m_{g} h_{g}\right)
\end{aligned}
$$

$$
\begin{aligned}
& \text { Or } \\
& \left\{\left(1-\alpha_{m w}\right) \frac{\partial\left[\rho_{f} h_{f}-\rho_{g} h_{s}\right]}{\partial p} V_{m}+\left(\frac{\partial \rho_{f} h_{g}}{\partial p}-1\right) V_{d}+m_{d} C_{p} \frac{\partial t_{g n t}}{\partial p}\right\} \frac{d p}{d t}+(1- \\
& \left.x_{m w}\right)\left(\rho_{f} h_{f}-\rho_{g} h_{g}\right) A_{d} \frac{d y}{d t}-\left(\rho_{f} h_{f}-\rho_{g} h_{g}\right) V_{m} \frac{d x_{m w}}{d t}=\left(m_{r} h_{r}-m_{d v} h_{f}\right)+ \\
& \left(m_{f w} h_{f W}-m_{g} h_{g}\right)
\end{aligned}
$$

This can be simplified with the aid of eq. (21) to

$$
\begin{aligned}
& \left\{C p_{10}\left(1-\alpha_{m v}\right) V_{m}-C p_{r} h_{r}+C p_{11}\right\} \frac{d p}{d t}-C x_{r} \rho_{f g} h_{r} \frac{d x_{r}}{d t}+ \\
& \left\{\frac{V_{w}-W_{d e}-(1-a v) w_{r}}{v_{m}}\right\}\left(\rho_{f} h_{f}-\rho_{g} h_{g}\right) A_{d} \frac{d y}{d t}-\left(\rho_{f} h_{f}-\rho_{g} h_{g}\right) V_{m} \frac{d \propto_{m v}}{d t}= \\
& x_{r} h_{f g} m_{d e}+\left(m_{f w} h_{f w}-m_{g} h_{g}\right) \\
& \left\{\begin{array}{l}
C p_{10}=\frac{\partial\left(\rho_{f} h_{f}-\rho_{g} h_{g}\right)}{\partial p}, \quad \text { and } \\
C p_{11}=\left(\frac{\partial \rho_{g} h_{g}}{\partial p}-1\right) V_{d}+m_{d} C_{p} \frac{\partial t_{s a t}}{\partial p}
\end{array}\right.
\end{aligned}
$$

It is important to realize that the volume of water in the drum mixture $\left(1-\propto_{m v}\right) V_{m}$ is given in terms of ${ }^{\propto_{m}}$ instead of the traditional states to emphasize the coupling between the states of the system.

The properties of water at the equilibrium operating conditions are evaluated using the $\mathrm{x}$ steam freeware MATLAB file, implementing the standard formulas given by the International Association for the Properties of Water IAPWS-IF97.

\section{State Space Analysis}

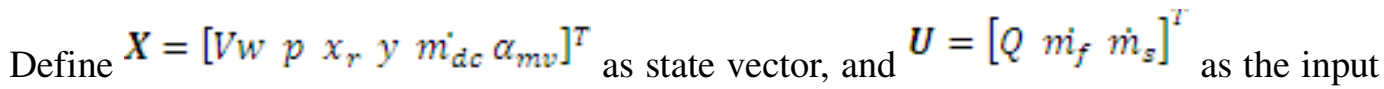
vector. Equations (9), (10), (19), (23), (34), and (36) can have the form

Journal of Engineering Sciences, Assiut University, Faculty of Engineering, Vol. 41, No. 5, September, 2013, E-mail address: jes@aun.edu.eg 


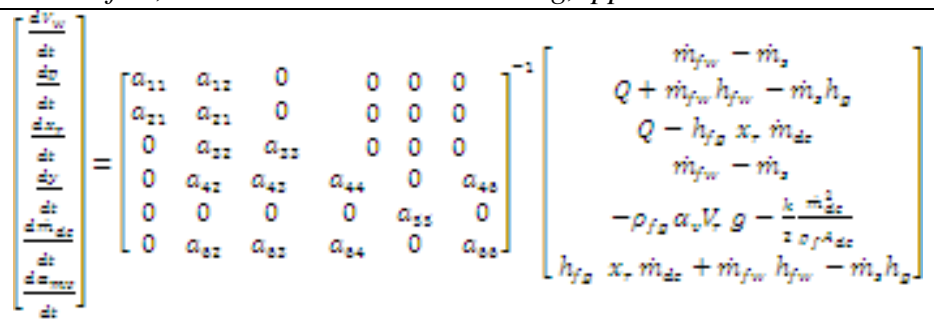

Where

$$
\begin{aligned}
& a_{11}=-\rho_{\mathrm{fg}} \\
& \mathrm{a}_{12}=C p_{1} \hat{V}_{v g}+C p_{2} \\
& \mathrm{a}_{21}=\rho_{\mathrm{f}} \mathrm{h}_{\mathrm{f}}-\rho_{\mathrm{g}} \mathrm{h}_{\mathrm{g}} \\
& \mathrm{a}_{22}=\mathrm{Cp}_{3} \mathrm{~V}_{\mathrm{w}}+C \mathrm{Cp}_{4} \\
& \mathrm{a}_{32}=\mathrm{Cp}_{5}-\mathrm{h}_{\mathrm{r}} \mathrm{Cp}_{6} \\
& \mathrm{a}_{33}=\mathrm{Cxr}_{1}-\mathrm{h}_{\mathrm{r}} \mathrm{CXr}_{2}, \\
& \mathrm{a}_{42}=\left[\left(\frac{\partial \rho_{f}}{\partial p}-\frac{\partial \rho_{g}}{\partial p}\right)\left(V_{w}-V_{d e}-\left(1-\alpha_{w}\right) V_{r}\right)+\frac{\partial \rho_{g}}{\partial p} V_{d}-C p_{r}\right] \text {, } \\
& \mathrm{a}_{43}=-C x_{\mathrm{r}} \rho_{\mathrm{fg}}, \\
& \mathrm{a}_{44}=-\left(1-\alpha_{\mathrm{mw}}\right) \rho_{f g} A_{d} \\
& \mathrm{a}_{46}=\rho_{f g} V_{m,} \\
& \mathrm{a}_{55}=L_{r}+L_{\text {de }} \\
& \mathrm{a}_{62}=C p_{10}\left(1-\propto_{m w}\right) V_{m}-C p_{r} h_{r}+C p_{11} \text {, } \\
& \mathrm{a}_{63}=-C x_{r} \rho_{f g} h_{r},
\end{aligned}
$$

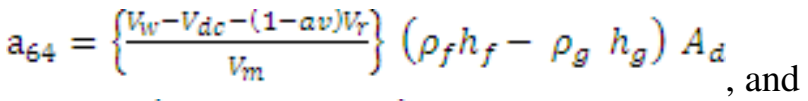

$$
\begin{aligned}
& \mathrm{a}_{66}=-\left(\rho_{f} h_{f}-\rho_{g} h_{g}\right) V_{m,}
\end{aligned}
$$

The above equation is equivalent to the form

$$
\ddot{\boldsymbol{X}}(t)=f(\boldsymbol{X}(t), \boldsymbol{U}(t))
$$

Where, $f(\boldsymbol{X}(t), \boldsymbol{U}(t))$, is a nonlinear functions of the states and the inputs of the system. Suppose ${ }^{\bar{x}}$ is an equilibrium point with equilibrium input ${ }^{\bar{u}}$. Assume the system starts a little bit away from ${ }^{\bar{x}}$ with a slightly different input ${ }^{\bar{u}}$. Define the deviation variables

$$
\begin{aligned}
& \boldsymbol{x}(t)=\boldsymbol{X}(t)-\bar{x} \\
& \boldsymbol{u}(t)=\boldsymbol{U}(t)-\bar{u}
\end{aligned}
$$

Jacobean linearization of the system gives

$$
\dot{x}(t)=A x+B u
$$

Where

Journal of Engineering Sciences, Assiut University, Faculty of Engineering, Vol. 41, No. 5, September, 2013, E-mail address: jes@aun.edu.eg 


$$
\begin{aligned}
& A=\left.\left.\frac{\partial f}{\partial X}\right|_{\substack{X=\bar{x} \\
U=\overline{\bar{M}}}} \overline{B f}\right|_{\substack{X=\overline{\bar{x}} \\
U=\overline{\mathrm{M}}}}
\end{aligned}
$$

Matlab code is used to simulate the response of the system while the symbolic toolbox of Matlab is used in the linearization process of the resulting system.

\section{Results and Discussion}

Testing and verification of the presented nonlinear model using parameters quoted from [22] is used to compare the simulation results under identical environmental conditions. A list of the parameters used is shown in table (1).

Table 1.

Design parameters and operating conditions of the simulated boiler

\begin{tabular}{|l|l|}
\hline Drum pressure $\mathrm{P}_{\mathrm{d}}$ & $8.5 \mathrm{MPa}$ \\
\hline Drum volume $\mathrm{V}_{\mathrm{d}}$ & $40 \mathrm{~m}^{3}$ \\
\hline Steam flow rate $m_{g}$ & $50 \mathrm{~kg} / \mathrm{s}$ \\
\hline Feed water flow rate $m_{f w}^{\mathrm{a}}$ & $50 \mathrm{~kg} / \mathrm{s}$ \\
\hline Riser volume $\mathrm{V}_{\mathrm{r}}$ & $37 \mathrm{~m}^{3}$ \\
\hline Heating rate & $86 \mathrm{Mw}$ \\
\hline Downcomer volume $\mathrm{V}_{\mathrm{dc}}$ & $11 \mathrm{~m}^{3}$ \\
\hline Drum water surface area & $20 \mathrm{~m}^{2}$ \\
\hline Riser metal mass $m_{t}$ & $160000 \mathrm{~kg}$ \\
\hline Steam quality & 0.051 \\
\hline $\begin{array}{l}\text { Riser \& downcomer mass } \\
\text { flow rate }\end{array}$ & $1194 \mathrm{~kg} / \mathrm{s}$ \\
\hline $\begin{array}{l}\text { Initial volume of the steam } \\
\text { water mixture in the drum }\end{array}$ & $24 \mathrm{~m}^{3}$ \\
\hline Total volume of water & $57.1 \mathrm{~m}^{3}$ \\
\hline Specific heat of metal & $0.5 \mathrm{~kJ} / \mathrm{kg}$ \\
\hline Total metal mass & $300000 \mathrm{~kg}$ \\
\hline Volumetric mixture fraction & $0.21 \mathrm{~m}^{3}$ \\
\hline Level of the water & $1.47 \mathrm{~m}$ \\
\hline Feed water temperature & $\mathbf{3 7} \mathrm{C}$ \\
\hline k/ $\beta$ & $25 / 0.3$ \\
\hline
\end{tabular}

Fig. 3 shows the open loop responses of the system for a $10 \mathrm{Mw}$ step change in heat addition compared to [22]. Since the input conditions, and the parameters used are identical, responses show close matching between the total water volumes, drum pressures. Slight difference in riser exit steam quality is shown in the figure which can be attributed to the insufficient data about metal masses. The figure also shows little discrepancy in the

Journal of Engineering Sciences, Assiut University, Faculty of Engineering, Vol. 41, No. 5, September, 2013, E-mail address: jes@aun.edu.eg 
volume of steam as expressed by steam level contribution. This can be explained, since the current model incorporates balance equations to evaluate the volume of steam instead of the empirical model and assumptions used in [22].

It is shown in the figure that the increase of pressure is accompanied by an increase in total water volume. This is mainly due to the condensation of steam caused by increasing the saturation pressure which explains the decrease of the volume of steam known as the shrink phenomenon.
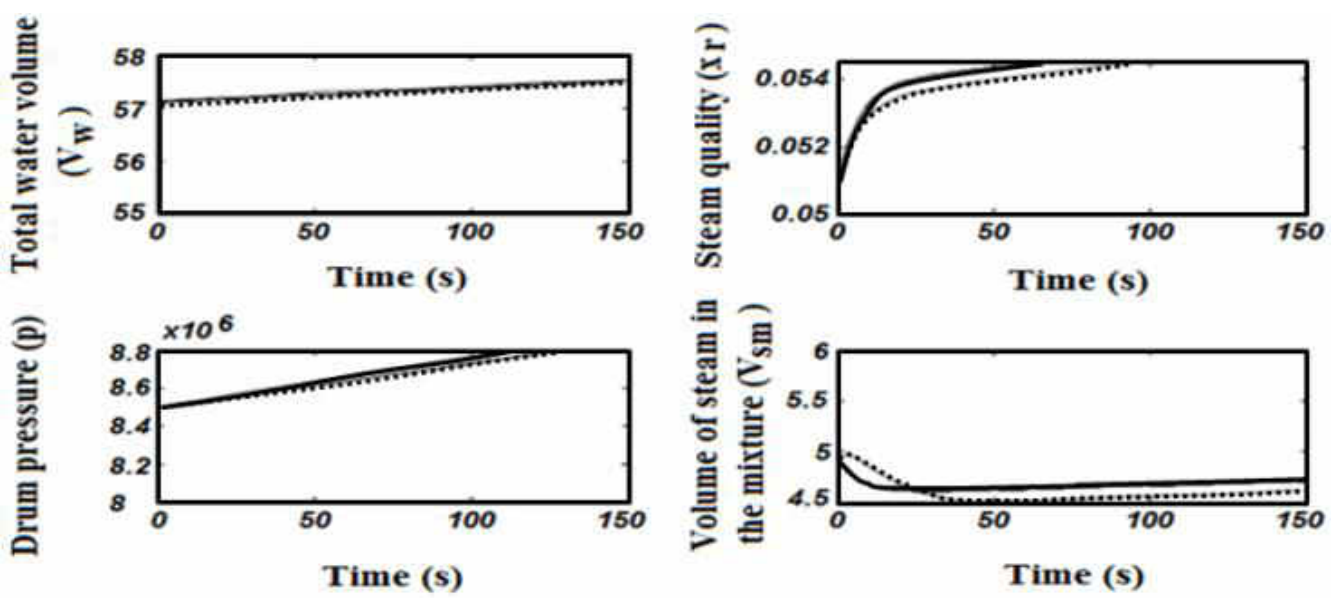

Fig. 3. Open loop responses for a step change of $10 \mathrm{Mw}$ in heat added (solid) presented and (dotted) Åström's.

The comparison due to $10 \mathrm{~kg} / \mathrm{s}$ step change in steam demand is shown in fig. 4. The results show close matching in total water volumes and drum pressures with little mismatching in riser exit steam qualities. The volumes of steam in the mixtures show discrepancy as is the case in figure (3) due to the same reasons. The decrease of pressure shown in fig. 4 is accompanied by a decrease of total water volume due to the evaporation resulting from the lower saturation pressure which explains the increase of the volume of steam in the drum water mixture.

Drum level comparisons due to a step change of $10 \mathrm{Mw}$ in heat added (a) and to $10 \mathrm{~kg} / \mathrm{s}$ step change in steam demand (b) are shown in fig. 5. The figure show better agreement in the case of step changes in heat added than in the case of step change in steam demand. The discrepancies of results due to changes in steam demand are expected as is explained in the discussion of figures (3) \& (4) before. The shrink/swell phenomena appears in the figure as the addition of heat is accompanied by an increase in the drum water level or swelling and the increase of steam demand is accompanied by a decrease of water level or shrinking. Apparently water level does not correctly reflect the actual change of water storage in the loop which causes non-minimum-phase behavior of level dynamics and suggests suitable compensation for better control of the level.

Journal of Engineering Sciences, Assiut University, Faculty of Engineering, Vol. 41, No. 5, September, 2013, E-mail address: jes@aun.edu.eg 

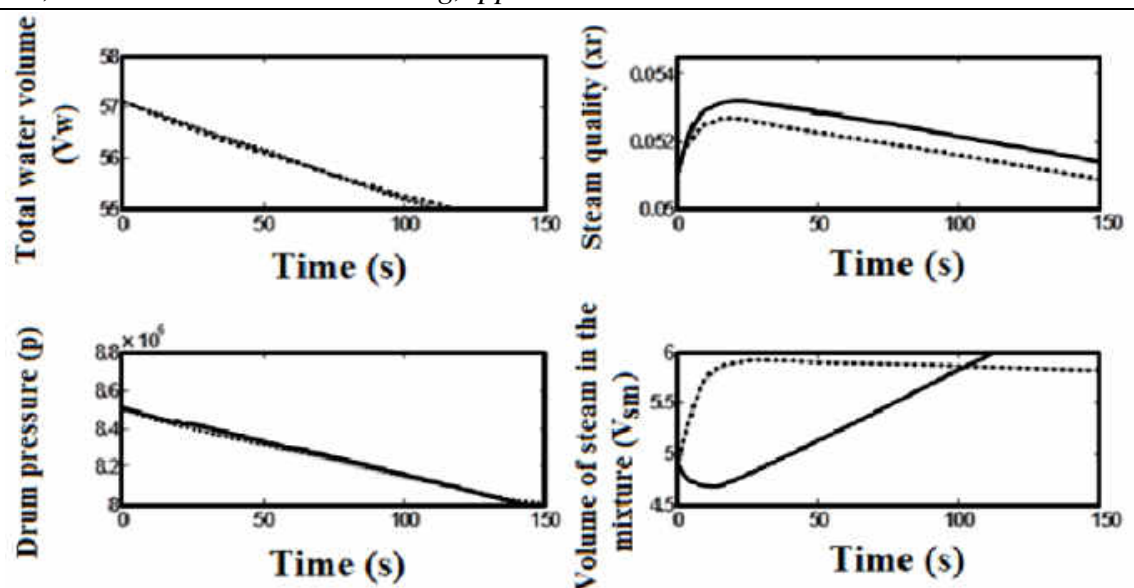

Fig. 4. open loop responses for a step change of $10 \mathrm{~kg} / \mathrm{s}$ in steam demand; (solid) presented and (dotted) Åström's.

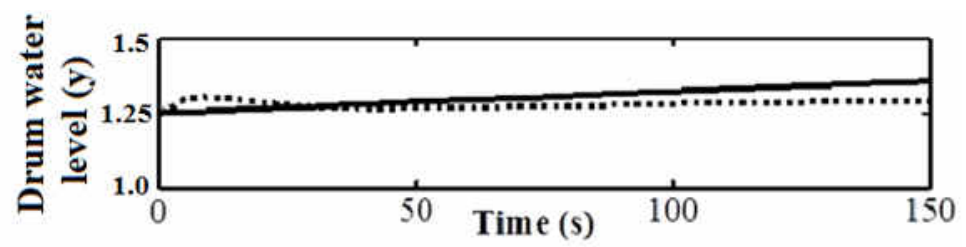

(a)

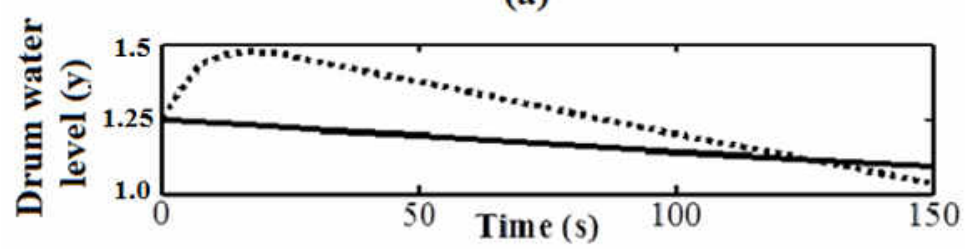

(b)

Fig. 5. open loop level responses for step changes in: (a) $10 \mathrm{Mw}$ heat added, (b) 10 $\mathrm{kg} / \mathrm{s}$ steam demand.

The volume of water in the drum can easily be evaluated using the state ${ }^{x_{m v}}$ as shown below.

$$
V_{w m}=\left(1-x_{m w}\right) V_{m}
$$

Since ${ }^{x_{m v}}$ is introduced only in this work. To validate using it, the volume of water in the drum is also evaluated using equation (33).

Almost identical values of the volume of water in the drum using both of the relations are shown in fig. (6), for step changes in heat addition and steam demand respectively. The

Journal of Engineering Sciences, Assiut University, Faculty of Engineering, Vol. 41, No. 5, September, 2013, E-mail address: jes@aun.edu.eg 
correspondence of these results validates the state ${ }^{x_{m w}}$ as the steam volumetric ratio which directly means that evaluation of the volume of steam in the mixture $V_{s m}$ is possible using it as follows:

$$
V_{s m}=x_{m v} V_{m}
$$

This means that the volume of steam in the mixture $V_{s m}$ can be accurately obtained from basic balance equations, which is not the case in the literature available, since the state ${ }^{x_{m w}}$ is not introduced there. Instead, some empirical relations and assumptions are used to evaluate it as for example the case in [22].

The importance of the model developed in this work comes from the direct evaluation of the drum level using the state $y$ incorporated in the model. State ${ }^{x_{m v}}$ is required to evaluate the level. The control of the drum level is essential for safe and efficient operation of the boiler. The models available in the literature do not include the drum level as a state which complicates the design of the level controller.

Åström \& Bell [22] used the summation of both the changes of the volume of steam and water in the mixture to evaluate the change of volume of the drum mixture and consequently use the area of the surface to evaluate the drum level.

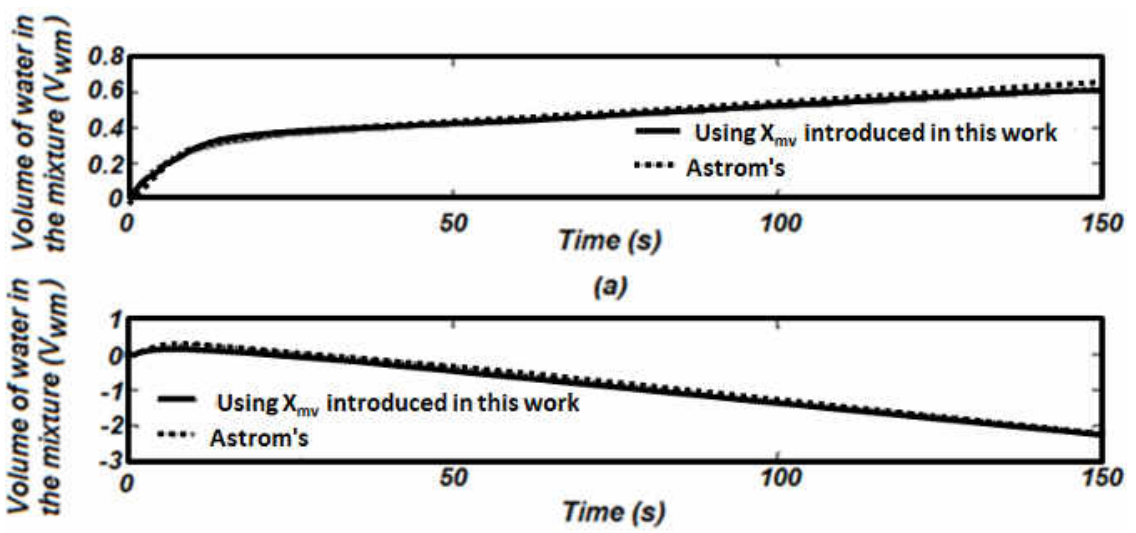

(b)

Fig. 6. Open loop responses for step changes in: (a) $10 \mathrm{Mw}$ heat added, (b) $10 \mathrm{~kg} / \mathrm{s}$ steam demand.

The results of fig. 7 show the volumetric steam ratio in the mixture, the corresponding volumes of steam and water and the drum level due to $10 \mathrm{Mw}$ a step change in heat added. It is shown in the figure that the addition of heat causes a decrease in the volumetric steam ratio and the volume of steam with an increase in water volume. As previously shown in fig. 3, this is mainly due to the increase of pressure which raises the saturation temperature and causes condensation of steam. The resulting level response shows an increase of the drum level with the increase of pressure.

Fig. 8 shows that a step change of $10 \mathrm{~kg} / \mathrm{s}$ in steam demand causes an initial decrease in the steam volumetric ratio followed by a large increase in its value. This is mainly due to the decrease of pressure as shown in fig. 4 which lowers the saturation temperature causing

Journal of Engineering Sciences, Assiut University, Faculty of Engineering, Vol. 41, No. 5, September, 2013, E-mail address: jes@aun.edu.eg 
S. R. Tawfeic, Boiler Drum-Level Modeling, pp. 1812 - 1829

the evaporation of steam. The corresponding volumes of steam and water are shown in the figure. The net result is a decrease of the drum level.

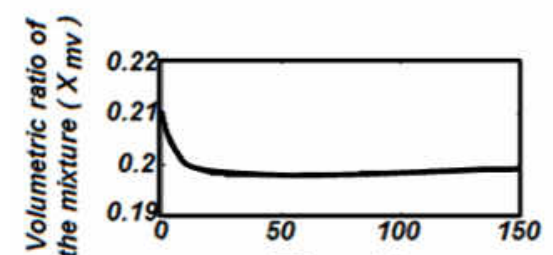

Time (s)
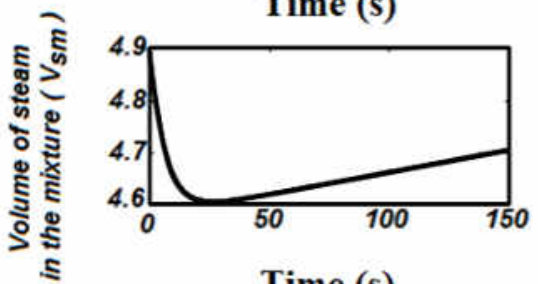

Time (s)

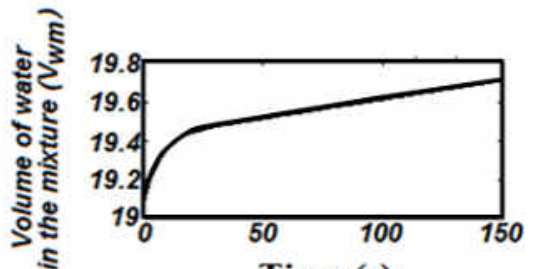

Time (s)

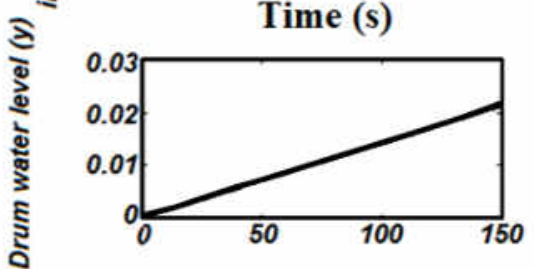

Time (s)

Fig. 7. Open loop response for a step change of $10 \mathrm{Mw}$ in heat added
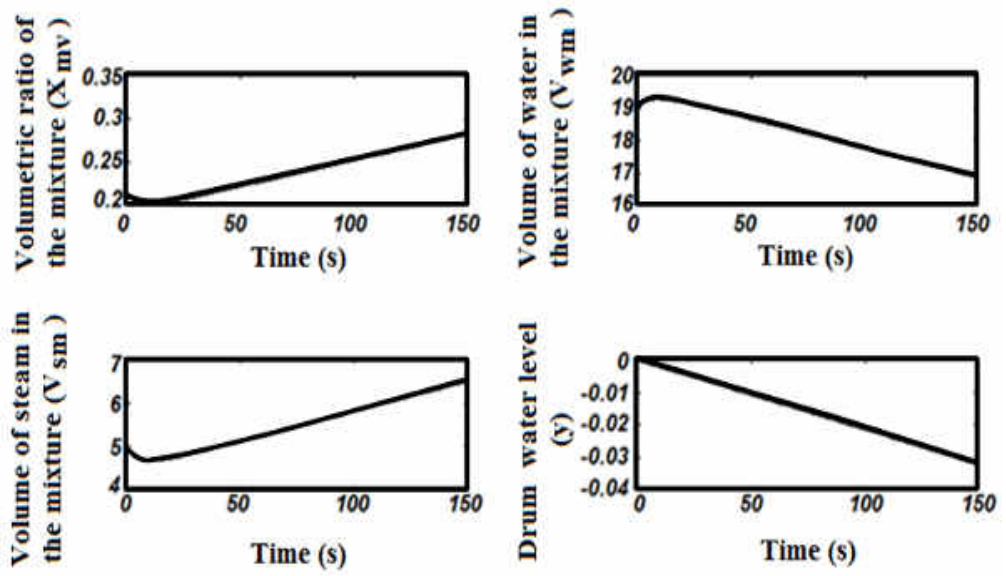

Fig. 8. Open loop responses for a step change in steam demand

Fig. 9 shows the riser and downcomer flow rates corresponding to the step changes in heat addition and steam demand respectively.

Journal of Engineering Sciences, Assiut University, Faculty of Engineering, Vol. 41, No. 5, September, 2013,E-mail address: jes@aun.edu.eg 


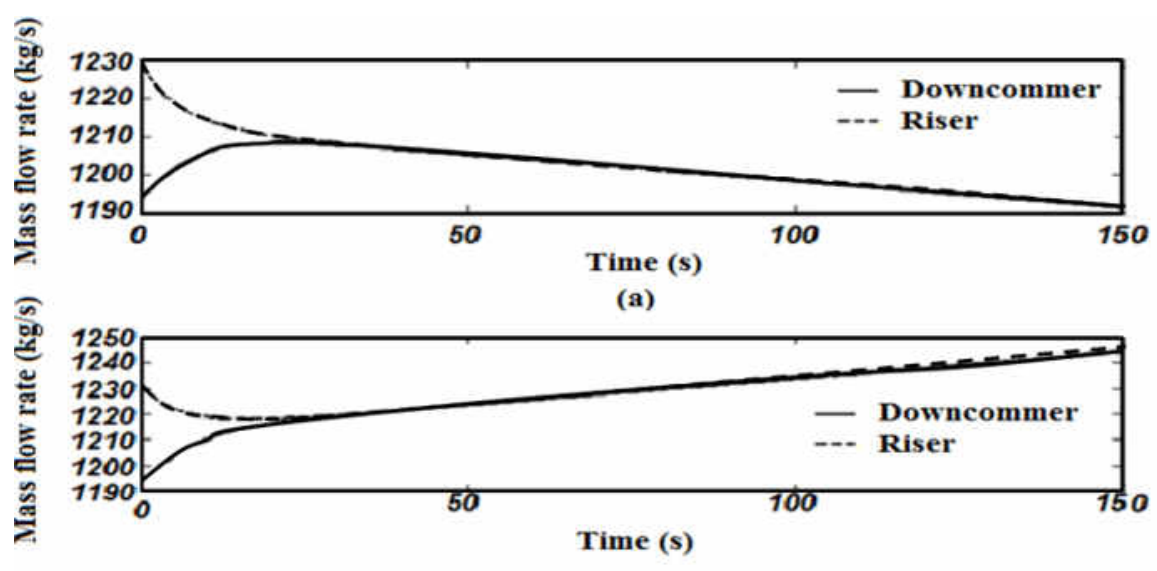

(b)

Fig. 9. Open loop responses for step changes in: (a) $10 \mathrm{Mw}$ heat added, (b) $10 \mathrm{~kg} / \mathrm{s}$ steam demand

Fig. 10 shows the drum level response for step changes in heat added and steam demand respectively assuming $\pm 10 \%$ change of the total metal masses around the original value as given in table (1). The results show the effect of varying drum metal mass on the dynamic response of the boiler. An important parameter affecting the dynamics of the drum level is the metallic masses of the boiler specially the drum metal mass. The dynamics of the exchange of energy between the metallic masses and the working fluid plays an important role in damping any rapid increase in drum level since the larger mass of the drum and tubes is accompanied by higher heat capacity which slows down the rate of exchange of heat.

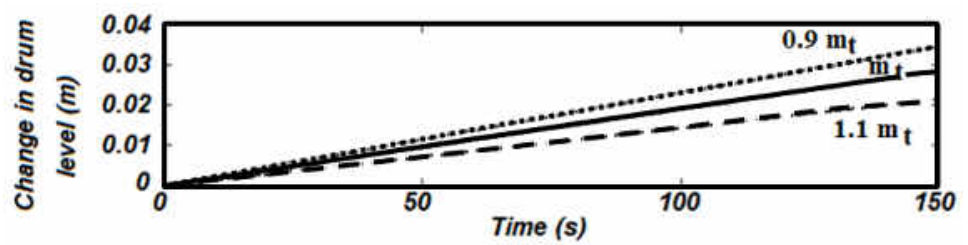

(a)

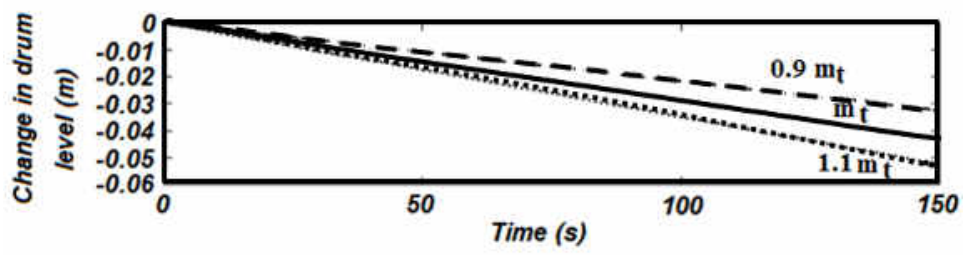

(b)

Journal of Engineering Sciences, Assiut University, Faculty of Engineering, Vol. 41, No. 5, September, 2013,E-mail address:jes@aun.edu.eg 
Fig. 10. Open loop responses for step changes in: (a) $10 \mathrm{Mw}$ heat added, (b) 10 $\mathrm{kg} / \mathrm{s}$ steam demand

\section{Conclusions}

In this paper a non-linear model describing the water level dynamics of natural circulation drum-type boilers has been developed. The model has six states and accounts for the total mass and energy inside the boiler, the riser tubes and the drum. The distribution of steam in the riser tubes and the drum and the shrink/swell phenomenon are also captured. Another important issue that affects the dynamics of the process is the exchange of energy between the working fluid and the boiler metallic walls and is captured by the model. Unlike many of the available literature, the drum water level is incorporated as a state in the model presented in this work giving rise to the chance of designing better level controllers.

\section{Notations}

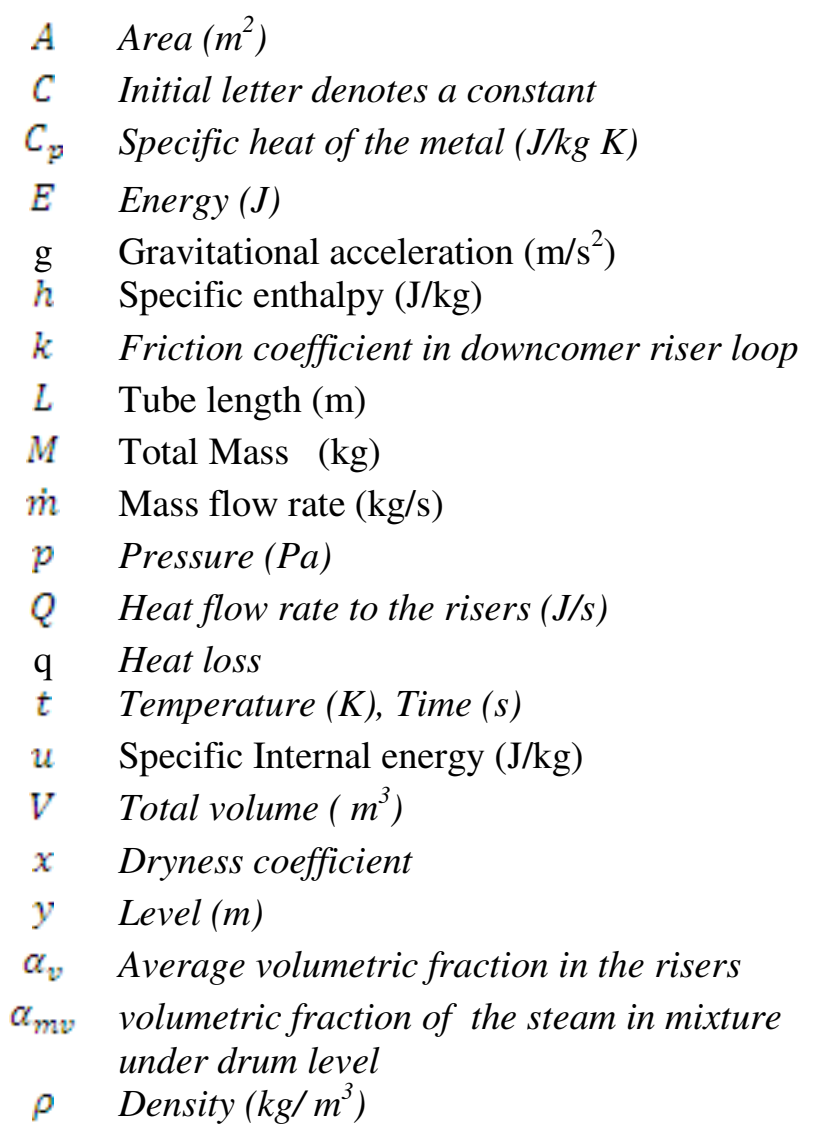

Journal of Engineering Sciences, Assiut University, Faculty of Engineering, Vol. 41, No. 5, September, 2013,E-mail address: jes@aun.edu.eg 


\section{Subscripts}

$\begin{array}{cl}\text { amb } & \text { Ambient } \\ \text { sat } & \text { Saturation condition } \\ d & \text { drum } \\ d c & \text { Downcomer } \\ e & \text { Equilibrium condition } \\ f & \text { Saturated liquid } \\ f g & \text { Phase change from liquid to gas } \\ f w & \text { Feed water } \\ g & \text { Saturated steam } \\ m & \text { Mixture of water and steam below drum } \\ & \text { water level, metal } \\ \mathrm{md} & \text { Mass of drum metal }(\mathrm{kg}) \\ \mathrm{mt} & \text { Mass of total boiler metal }(\mathrm{kg}) \\ o & \text { Initial value } \\ r & \text { Riser } \\ s & \text { Saturated steam } \\ \mathrm{w} & \text { Saturated water } \\ t & \text { total value } \\ \end{array}$

\section{References}

[1] Wen Tan, Horacio J. Marquez, Tongwen Chen, \& Jizhen Liu. (2005). Analysis and control of a nonlinear boiler-turbine unit. Journal of process control, 15, 883-891.

[2] Wen Tan, Fang Fang, Liang Tian, Caifen Fu, Jizhen Liu. (2008). Linear control of a boilerturbine unit: Analysis and design. ISA transactions, 47, 189-197.

[3] Eun. Gee. Kim, (1990). Control system design of boiler drum level. Proceedings of ISL winter workshop, 3, 43-54.

[4] Caifen Fu, Jizhen Liu, \& Wen Tan, (2004). Robust PI design for a benchmark nonlinear boiler. 5th Asian control conference, vol1, (pp. 304-308). Australia, July 20-23, ,

[5] Wen Tan, Jizhen Liu, \&Yanqiao Chen. (2004). Tuning of PID Controllers for boiler-turbine units. ISA transactions. 43, 571-583.

[6] Hamdi A. Awad, Saad M. Hewaidy, (2005). A serial distributed multi- variable fuzzy controller for boiler systems. Al-Azher University Engineering Journal AUEJ'05, 8, 45-59.

[7] Addel Ben-Abdennour, Kwang Y. Lee, (1996). An autonomous control system for boilerturbine units. IEEE transactions on energy conversion, 11, 2, 401-406.

[8] Ali Ghaffari, Mansour Nikkhah Bahrami \& Hesam Parsa, (2006). Turbine Follower Control Strategy Design Based on Developed FFPP Model. International Journal of Intelligent Systems and Technologies 1; 1, 38-846.

[9] Hèctor, G.C., Alfredo C.D., Jose A. R. \& Ahmet Palazoglu. (1995). Variable Structure Control with a Second Order Sliding Condition: Application to a steam generator. Automatica, 31, no. 8, 1157-1168.

[10] Yu Nanhua, Ma Wentong, \& Su Ming. (2006). Application of adaptive gray predictive algorithm to boiler drum level control. Energy Conversion \& Management, 46, 2999-3007.

Journal of Engineering Sciences, Assiut University, Faculty of Engineering, Vol. 41, No. 5, September, 2013, E-mail address: jes@aun.edu.eg 
S. R. Tawfeic, Boiler Drum-Level Modeling, pp. 1812 - 1829

[11] W. J. Peet, T. K. P. Leung (1995). Development and Application of a Dynamic Simulation Model for a Drum Type Boiler with Turbine Bypass System. International Power Engineering Conference, Singapore, 27 Feb - 1 March.

[12] Pang-Chia Chen, Jeff S. Shamma. (2004). Gain-scheduled 11-optimal control for boilerturbine dynamics with actuator saturation. Journal of Process Control, 14, 263-277.

[13] Bin Li, Tingkuan Chen, Dong YangBin Li, Tingkuan Chen, Dong Yang, (2005). DBSSP - A computer program for simulation of controlled circulation boiler and natural circulation boiler start up behavior. Energy Conversion and Management 46, 533-549.

[14] Tuomas Kataja, Yrjö Majanne. Dynamic Model of a Bubbling Fluidized Bed Boiler. The 48th Scandinavian Conference on Simulation and Modeling, Sweden, December 2007.

[15] Heimo Walter, (2007). Dynamic simulation of natural circulation steam generators with the use of finite-volume-algorithms - A comparison of four algorithms. Simulation Modeling Practice and Theory, 15, 565-588.

[16] K.L. Lo \& Y. Rathamarit, (2008). State estimation of a boiler model using the unscented Kalman filter. The Institution of Engineering and Technology IET Gener. Transm. Distrib, Vol. 2, No. 6, pp. 917-931.

[17] Adam, E.J. \&Marchetti, J.L. (1999). Dynamic simulation of large boilers with natural recirculation. Computers and Chemical Engineering,.23, 1031-1040.

[18] L. C. Gómez \& F. E. Milioli, June (2005). Numerical Simulation of Fluid Flow in CFB Risers - a Turbulence Analysis Approach. Journal. of the Braz. Soc. of Mech. Sci. \&Eng Vol. XXVII, No. 2 / 141

[19] M.H. Zhang, K.W. Chu, F. Wei, A.B. Yu, (2008). A CFD-DEM study of the cluster behavior in riser and downer reactors. Powder Technology 184, 151-165.

[20] H.E. Emara-Shabaik, M.A. Habib, I. Al-Zaharna, (2008). Prediction of risers tubes temperature in water tube boiler. Applied mathematical modeling, 33, 1323-1336;

[21] H. Kim, S. Choi, (2005). A model on water level dynamics in natural circulation drum-type boiler. International Communications in Heat and Mass Transfer, 32, 768-796.

[22] Åström, K.J. \& Bell, R.D. (2000). Drum-boiler dynamics. Automatica, 36, 363-378.

[23] F. M. Mansour, A. M. Abdul Aziz, S. M. Abdl-Ghany, \& H. M. El-shaer, (2007). Combined Cycle Dynamics. Proc. Instn Mech. Engrs vol. 217 Part A: J. power and Energy.

[24] K. Eklund, Linear mathematical models of the drum - riser loop of a drum boiler. Lund Institute of Technology, Division of Automatic Control, Report 6809, November 1968.

\section{نمذجة منسوب اسطوانة الغلاية}

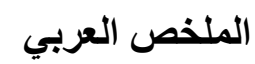

في هذا البحث تم تطوير نموذج رياضي لوصف ديناميكا الحركة لمنسوب المياه داخل غلايات السريان الحر.

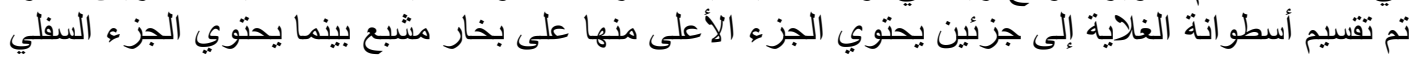

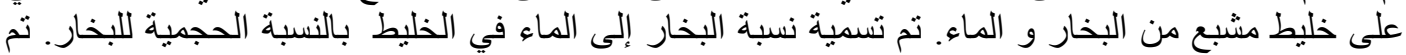

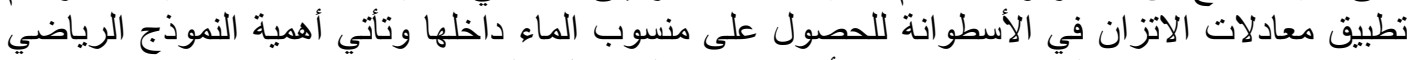

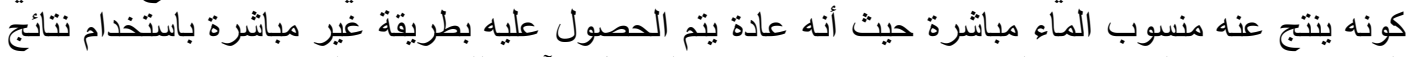

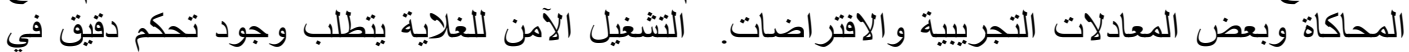

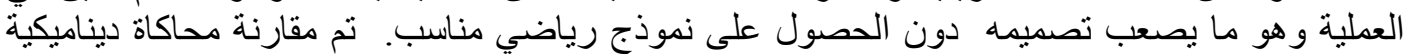

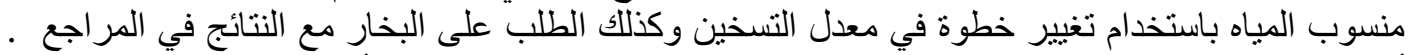
أظهرت النتائج إمكانية الحصول على منسوب المياه فعدل المباه باستخدام معادلات الاتز ان الأساسية.

Journal of Engineering Sciences, Assiut University, Faculty of Engineering, Vol. 41, No. 5, September, 2013, E-mail address: jes@aun.edu.eg 